\title{
Quantifying the relative impact of hunting and oiling on Brünnich's guillemots in the North-west Atlantic
}

\author{
Morten Frederiksen ${ }^{1}$, Jannie F. Linnebjerg ${ }^{1,2}$, Flemming R. Merkel ${ }^{1,2}$, Sabina I. Wilhelm ${ }^{3}$ \& Gregory J. Robertson ${ }^{3}$ \\ 'Department of Bioscience, Aarhus University, Roskilde, Denmark; \\ ${ }^{2}$ Greenland Institute of Natural Resources, Nuuk, Greenland; \\ ${ }^{3}$ Environment and Climate Change Canada, Mount Pearl, Newfoundland and Labrador, Canada
}

\begin{abstract}
Brünnich's guillemot (Uria lomvia), or thick-billed murre, is an abundant pan-Arctic seabird, but several Atlantic breeding populations are declining. The species is subject to traditional harvest in the important wintering areas off west Greenland and Newfoundland, and has been subject to chronic oil pollution on the east coast of Canada. Until recently, knowledge of winter distribution has been insufficient to assess the impact of these mortality sources on specific breeding populations. We collate existing information on mortality from bag statistics in Greenland and Canada and studies of oiling off Newfoundland, as well as new data on age distribution in the harvest. Based on the results of recent tracking studies, we construct a spatially explicit population model that allocates hunting and oiling mortality to breeding populations and estimates the relative impact on their growth rate. Results indicate that annual population growth rate is depressed by $0.011-0.041$ (approximately $1 \%-4 \%$ ) by anthropogenic mortality sources. In addition to affecting local breeders, hunting in Greenland mainly affects declining breeding populations in Svalbard and Iceland, while hunting and oiling in Newfoundland mainly affect guillemots breeding in Arctic Canada and north-west Greenland, where most populations are relatively stable. The strongest relative impact is predicted on the small breeding population in Atlantic Canada, which winters mainly on the Newfoundland Shelf and therefore is exposed to both hunting and oiling. Our results clarify the relationships between hunting in Greenland and Canada and growth of specific breeding populations, and thus have major implications for harvest management of guillemots.
\end{abstract}

\section{Introduction}

Many migratory birds are exposed to anthropogenic mortality sources in their wintering areas; the impact of this mortality on specific breeding populations is determined by how much they mix in winter and their relative exposure to these winter mortality sources (Esler 2000). Assessing and managing this impact requires detailed knowledge of the species' migration patterns and non-breeding distribution. For seabirds, such knowledge has until recently been limited, and determining, for example, which breeding populations have been affected by specific major oil spills in winter has been problematic (Cadiou et al. 2004). However, recent tracking studies have vastly increased the available data on non-breeding distribution for many seabird species, and for some species the information is now sufficiently comprehensive that the composition of specific wintering populations can be estimated (Frederiksen et al. 2012).

One seabird species which is exposed to widespread, chronic anthropogenic mortality in its wintering range is Brünnich's guillemot (Uria lomvia), or thick-billed murre (hereafter guillemot). This abundant pan-Arctic species has long been a popular hunting object in its important Atlantic wintering areas off west Greenland and Newfoundland (Elliot et al. 1991; Falk \& Durinck 1992; Gaston \& Robertson 2010), although the number of birds shot has decreased substantially in both areas (Frederiksen et al. 2016). In addition, large numbers 
of guillemots have fallen victim to chronic oil pollution in the important shipping corridor off Newfoundland (Wiese \& Ryan 2003); the extent of this problem has been reduced recently by stricter regulation of discharges of oil and bilge water (Robertson et al. 2014). Nevertheless, the annual number of guillemots killed by hunting and oiling in the North-west Atlantic is still substantial (ca. 150 000; Robertson et al. 2014; Frederiksen et al. 2016). Guillemot populations are declining rapidly in many parts of the Atlantic breeding range, including Greenland (Merkel et al. 2014), Iceland (Garðarsson et al. 2019) and Svalbard (Descamps et al. 2013), and it is highly relevant for managers to assess the potential role of direct anthropogenic mortality in driving this decline, as well as the sustainability of guillemot hunting.

The recent compilation of tracking data from nearly all major Atlantic breeding guillemot populations formed the basis of estimating the composition of wintering populations in terms of breeding origin (Frederiksen et al. 2016). Here, we use the results of this study in combination with recent information on hunting and oiling mortality in Greenland and Canada to construct a spatially explicit population model that estimates the impact on growth rates of specific breeding populations. Our aim is to provide an improved basis for pan-Atlantic management of this declining migrant seabird. This study is an update and extension of the model presented by Wiese et al. (2004) for Canadian-breeding guillemots.

\section{Methods}

\section{Study areas and winter population composition}

Frederiksen et al. (2016) estimated the size and composition of wintering guillemot populations in the Atlantic based on tracking data from 320 individuals breeding in 18 colonies in Canada, Greenland, Iceland, Svalbard and mainland Norway. Here, we focus on three wintering areas with substantial anthropogenic winter mortality: SW Greenland Shelf, CW Greenland Shelf and Newfoundland Shelf (Fig. 1). Seven breeding populations of widely differing size were represented in these wintering areas in more than trivial numbers (i.e., estimated number of wintering adults $>1000$ ) and were therefore included in the population model: Atlantic Canada, Hudson Bay, Arctic Canada, north-west Greenland, south-west Greenland, Iceland and Spitsbergen (Fig. 1). Between 14\% and $51 \%$ of breeders from these populations used the focal wintering areas, and each area was estimated to hold several hundred thousand wintering breeders, in addition to unknown numbers of pre-breeders (Fig. 2). Populations breeding on Bjørnøya and in mainland Norway hardly used these wintering areas, whereas tracking data were missing for the populations breeding in east Greenland, on Jan Mayen and in Arctic Russia. Tracking data were only available for adult breeders. Recoveries of ringed birds show small differences in distribution between age classes (Donaldson et al. 1997; Bakken et al. 2003; Lyngs 2003), and here we assume that pre-breeders are distributed in the same way as adults.

\section{Hunting mortality and age and sex distribution, Greenland}

Data on reported hunting mortality of guillemots in Greenland were provided by the Ministry of Fisheries and Hunting, Government of Greenland, from the Piniarneq/LULI database (extracted 9 June 2017). Hunters report once a year on monthly bag numbers by logging on to the municipality website www.sullissivik.gl or by handing in a completed form with bag numbers at the local municipality office. The hunters are required to report on hunting to have their hunting license renewed. The reports date back to 1993, and here we used data for the period 2008/09-2015/16 when hunting regulations were unchanged (open season 15 October-28/29 February south of $67.5^{\circ} \mathrm{N}$ and 1 September-28/29 February north of $67.5^{\circ} \mathrm{N}$ ) and numbers reported shot were remarkably constant. Data in Piniarneq are broken down by administrative districts, and we summarized them for the wintering areas used by Frederiksen et al. (2016) (see also Fig. 1). Assuming equal sex ratio in the harvest (see Results section), we divided the reported number shot by 2 because the model represents females only. The mean number of females reported shot during the winter season (September-March) was 10614 (SD 977) on the SW Greenland Shelf, and 17658 (SD 2925) on the CW Greenland Shelf. The mean proportion of the harvest reported before 1 January was $66 \%$ in CW Greenland and 79\% on the SW Greenland Shelf.

Samples of freshly shot guillemots were collected irregularly during 1995-2017 on the CW Greenland Shelf (within approximately $50 \mathrm{~km}$ of Nuuk) and stored frozen at $-18^{\circ} \mathrm{C}$ (total $n=470$ ). All birds were dissected and measured by JFL and FRM during 2016-17. First-winter birds were distinguished from older birds by having an externally measured interorbital skull width of $<12.5 \mathrm{~mm}$ (Gaston \& Hipfner 2000). Where possible, this criterion was combined with the presence or absence of bursa fabricii, the size of testicles in males and the size of the oviduct in females (Nevins \& Carter 2003).

Because the proportion of first-winter birds in the harvest was higher before 1 January than after (see Results), we calculated a mean proportion for the CW Greenland Shelf as an average weighted by the numbers of birds reported shot during the two periods. We had no access to 


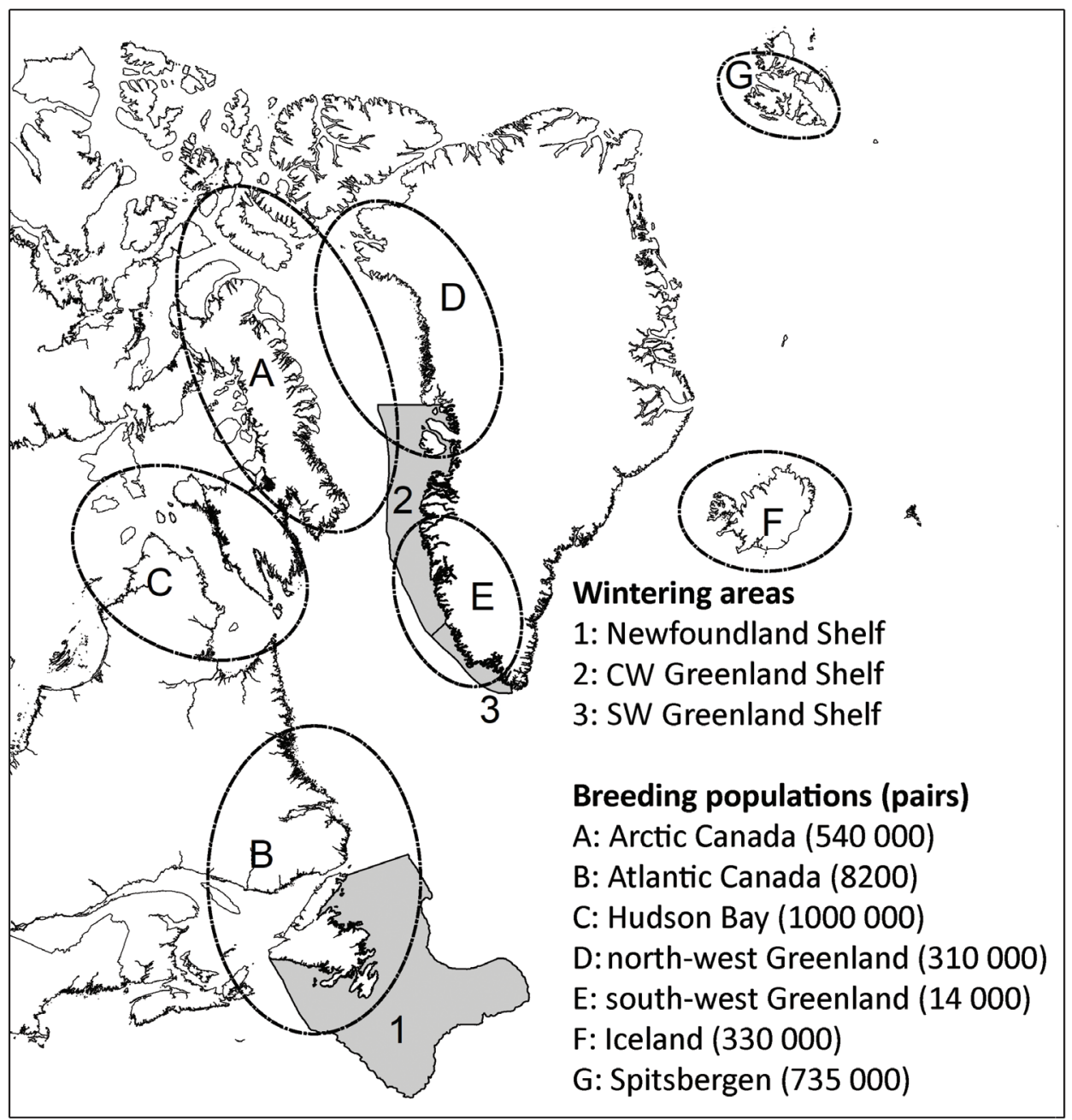

Fig. 1 Maps showing the focal wintering areas (grey shading) and the breeding populations involved (ellipses). The estimated number of pairs in each breeding population is shown in parentheses (data from Frederiksen et al. 2016).

recent samples of shot guillemots from the SW Greenland Shelf. Falk \& Durinck (1992) reported $>90 \%$ first-winter birds among shot birds in this area in 1988/89, but also suggested that this season was atypical and that a somewhat higher proportion of older birds would occur in most years. We assumed a higher proportion of firstwinter birds on the SW Greenland Shelf than on the CW Greenland Shelf (85\% before 1 January, 80\% after, weighted mean $84 \%$ ). In both areas, we used an SD of 0.05 in the stochastic model to reflect year-to-year variation in age distribution.

\section{Hunting mortality and age distribution, Canada}

Beginning in 2010, annual estimates of the recreational, non-Indigenous harvest of guillemots-Brünnich's as well as common guillemot (Uria aalge)—which is restricted to the province of Newfoundland and Labrador, have been collected as part of the Canadian National Harvest Survey (Gendron \& Smith 2017). All migratory game bird hunters in Canada, including guillemot hunters, are required to purchase a Migratory Game Bird Hunting Permit. At the time of purchase, hunters in Newfoundland and Labrador (average 16 049, range 15 109-17 548 between 2010 and 2016) are specifically asked if they intend to pursue guillemots. Subsequently, a geographically stratified random sample of approximately $25 \%$ of these self-identified guillemot hunters are asked to complete a calendar survey and record the numbers of guillemots harvested each day throughout the hunting season. This survey provides weekly estimates of guillemot harvest by the sampled hunters, which is combined with the results of the permit sales and numbers of self-identified guillemot hunters to estimate total weekly guillemot harvest. 
(a)

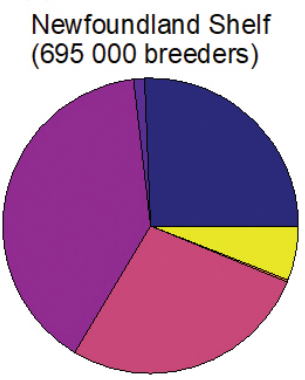

Arctic Canada

Atlantic Canada

Hudson Bay

north-west Greenland

south-west Greenland

$\smile$ Spitsbergen
CW Greenland Shelf (517 000 breeders)

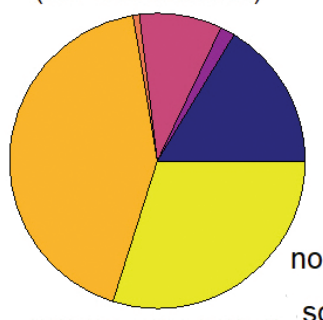

SW Greenland Shelf (295 000 breeders)

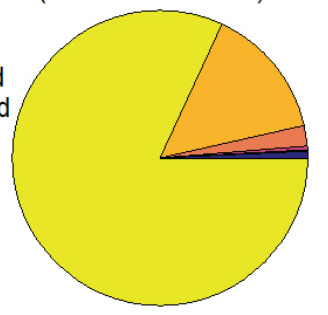

(b)

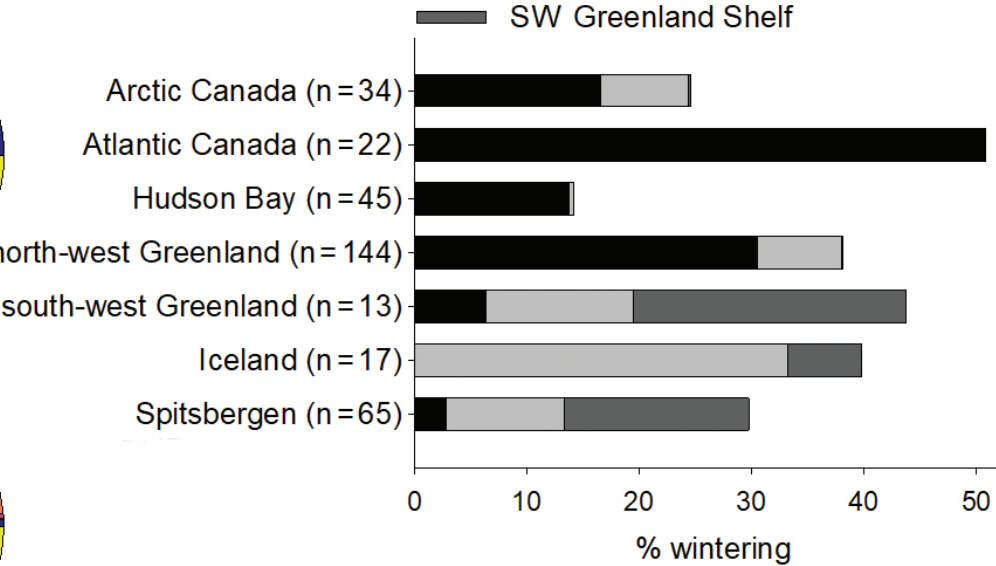

Fig. 2 (a) Composition of the wintering populations in the three focal areas, in terms of breeding origin. The total estimated number of breeding birds wintering in each area is shown in parentheses. (b) Percentage of each breeding population that winters in the three focal areas (data from Frederiksen et al. 2016). The estimates are based on 440 migration episodes (number of migration episodes for each of the breeding populations given in parentheses) of 320 tracked guillemots (including breeding populations not using the focal wintering areas).

During 2010-16, data from permit sales and hunter surveys led to estimates of an average of 3776 (range: 2284-4479) hunters in Newfoundland and Labrador who successfully hunted guillemots. The weekly estimates of numbers shot are summed across the entire hunting season, providing the total number of guillemots harvested in Newfoundland and Labrador each year. These estimates are available online (Gendron \& Smith 2017).

As both guillemot species are harvested in Canada, the proportion of Brünnich's guillemot in the harvest is estimated by a separate Species Composition Survey (Gendron \& Smith 2017). In this survey, a different geographically stratified random sample of hunters are sent a set of plastic-lined envelopes, with instructions on how to complete the information requested and mail in wings of guillemots that they harvested. The species and age of all wings are determined following Wilhelm et al. (2008), that is, plumage colour, numbers of faded greater secondary coverts and relative length of inner primaries and outer secondaries are used to assess species and age (first-winter or older) of each wing. These data provide annual estimates of the proportion of all guillemots being Brünnich's guillemot, and of the proportion being first-winter birds. We included data on harvest size and age distribution (total $n=1772$ Brünnich's guillemots, from an average of 24 hunters responding to the survey each year) from 2010 to 2016.
Sex ratios in the harvest are not collected regularly in Canada, although small localized collections suggest an even sex ratio, at least among adults (McFarlane Tranquilla et al. 2010). However, McFarlane Tranquilla et al. (2010) did note a male-biased sex ratio in harvested juveniles. For the purposes of the modelling, we assumed an equal sex ratio in the harvest for all age classes. Overall, the mean number of females reported shot during the open hunting season, which ranges between 1 September and 10 March but is restricted to 3.5 months in any one region, was 29621 (SD 8956). Harvest of guillemots by Indigenous peoples in Canada is very small and is not considered here (Priest \& Usher 2004).

\section{Oiling mortality, Canada}

Mortality from chronic oil pollution was obtained from estimates by Robertson et al. (2014), using the Oiled Seabird Mortality Model developed by Wiese $\&$ Robertson (2004). In summary, numbers of beached bird carcasses found on $3.5 \mathrm{~km}$ of weekly surveyed beaches in southeastern Newfoundland are used to extrapolate total mortality from chronic oiling in the region. Carcass persistence and detection on beaches, weather-specific drift patterns, carcass deposition rates and sinking rates are all accounted for with experimentally derived estimates specific to this region (Wiese \& Jones 2001; Wiese 2002, 2003). 
Table 1 Values (mean and SD) of demographic parameters used in the population model. For $S_{0}$, we sampled from the empirical distribution (which was very flat) rather than using a specified SD. Mean values used in the more pessimistic scenario are shown in brackets.

\begin{tabular}{|c|c|c|c|c|}
\hline Label & Parameter & Mean & SD & Source \\
\hline$S_{0}$ & First-year survival & 0.56 & $\begin{array}{c}{[0.40,0.31,0.52,0.91,0.30} \\
0.55,0.35,0.33,0.85,0.86 \\
0.67,0.77,0.52,0.73,0.75,0.67 \\
0.67,0.45,0.38]\end{array}$ & Harris et al. 2007 \\
\hline$S_{1}$ & Second-year survival & $0.79(0.75)$ & 0.033 & Harris et al. 2007 (SD assumed) \\
\hline $\mathrm{S}_{2}$ & Third-year survival & $0.92(0.85)$ & 0.033 & Harris et al. 2007 (SD assumed \\
\hline$S_{a}$ & Adult survival & $0.95(0.90)$ & 0.033 & Wiese et al. 2004; Smith \& Gaston 2012 \\
\hline $\mathrm{Pb}_{3}$ & Proportion of three-yr-olds breeding & 0.025 & - & Wiese et al. 2004 \\
\hline $\mathrm{Pb}_{4}$ & Proportion of four-yr-olds breeding & 0.367 & - & Wiese et al. 2004 \\
\hline $\mathrm{Pb}_{5}$ & Proportion of five-yr-olds breeding & 0.700 & - & Wiese et al. 2004 \\
\hline$P b_{\mathrm{ad}}$ & Proportion of adults breeding & 0.985 & - & Wiese et al. 2004 \\
\hline B & Breeding productivity & $0.69(0.49)$ & 0.088 & Smith \& Gaston 2012 \\
\hline $\mathrm{Sr}$ & Sex ratio & 0.5 & - & Assumed \\
\hline
\end{tabular}

Because of the relatively low numbers of carcasses found (64-332 annually), extrapolations of total bird mortality are based on all carcasses found, which are then assigned to species based on the relative frequency of each species among all carcasses found that year. We used estimates from 2009 to 2012 and, assuming that both sexes are equally susceptible to being oiled (48.2\% male; Robertson et al. 2006), the mean annual estimated number of females killed was 19709 (SD 16 512).

\section{Population model}

We constructed a stochastic female-only matrix population model with six age classes and a pre-breeding census (Caswell 2001). Demographic parameter values for the basic model were selected to represent optimal conditions, that is, a population not exposed to anthropogenic mortality and with near-optimal reproduction (Table 1). For pre-breeding survival, these values were taken from a long-term study of an unexploited population of the closely related common guillemot (Harris et al. 2007). Each of the seven breeding populations was initiated with a population size (breeding pairs) as by Frederiksen et al. (2016) and a stable age distribution defined by the demographic parameter values (Stubben \& Milligan 2007) (Table 2). Total female population size was calculated using the stable age distribution and age-specific proportions of breeders (Table 2). For simplicity, we assumed that anthropogenic mortality occurred at mid-winter, and the model populations were projected from year to year in two stages (autumn and spring) (see also Wiese et al. 2004; Gilliland et al. 2009). Age-specific natural mortality was allocated to the two stages by taking the square root of annual survival, except for first-winter birds where
Table 2 The total female population size at the pre-breeding census $(N P B)$, relative to the number of breeding pairs, was estimated based on the model stable age distribution $\left(S A_{i}\right)$ and the age-specific proportions of breeders $\left(P b_{i}\right)$. Total female population size at the start of the breeding season is thus 1.55 times the number of breeding pairs.

\begin{tabular}{lccc}
\hline Age class $i$ & $S A_{i}$ & $P b_{i}$ & $N P B_{i}=S A_{i} / \Sigma S A_{i} p b_{i}$ \\
\hline 1 & 0.118 & 0 & 0.183 \\
2 & 0.089 & 0 & 0.137 \\
3 & 0.077 & 0.025 & 0.120 \\
4 & 0.070 & 0.367 & 0.108 \\
5 & 0.063 & 0.700 & 0.098 \\
$6+$ (adult) & 0.583 & 0.985 & 0.902 \\
Total & 1 & & 1.548 \\
\hline
\end{tabular}

autumn survival was set to $S_{0} / \sqrt{S_{1}}$ and spring survival to $\sqrt{S_{1}}$, reflecting the assumption that enhanced natural mortality of juveniles occurred prior to mid-winter. During the first stage, reproduction and autumn natural mortality occurred. Winter anthropogenic mortality (in absolute numbers) was subtracted between stages, and spring natural mortality occurred during the second stage. The total number of females shot or killed by oiling was allocated to breeding populations based on the estimated composition of the wintering populations in the three focus areas. For oiling, we assumed that all age classes were equally vulnerable (Robertson et al. 2006) and allocated mortality proportional to their relative abundance, that is, age distribution after reproduction and autumn natural mortality. For hunting, we used empirical data (see above) to estimate the proportion of first-winter birds among all birds shot, and allocated the 
remaining mortality to older age classes proportional to their relative abundance (see also Wiese et al. 2004). We assumed that anthropogenic mortality was completely additive to natural mortality, which is typically the case for long-lived animals such as guillemots (Péron 2013), and consistent with a precautionary approach to harvest management (Government of Canada 2017).

Stochastic values of demographic parameters were generated by drawing random values from beta distributions with means and SDs from the literature (Table 1). Fecundity values in stochastic population models are typically drawn from normal or other distributions, but because guillemots can only produce a maximum of one chick each year, fecundity values are bounded between 0 and 1 and are effectively modelled as a beta distribution. However, for first-year survival the observed distribution was very flat, and we instead drew random values from the empirical distribution (Harris et al. 2007). To represent uncertainty in initial breeding population sizes, we assumed a coefficient of variation of $20 \%$ and drew values from normal distributions independently for each breeding population.

For Canadian mortality sources, random draws from the empirical distribution of harvest size for the years 2010-16 (seven estimates) and numbers oiled for the years 2009-2012 (four estimates) were taken for each simulation. Similarly, the proportion of first-winter guillemots in the harvest was taken as a draw from the empirical distribution from the same years (2010-16). For the Greenland harvest, we took random draws from the empirical distribution of harvest size 2008/09-2015/16 (eight estimates), whereas the proportion of first-winter birds was drawn from a beta distribution with the observed mean (see Results) and an assumed SD of 0.05 .

We ran 10000 stochastic realizations of the model. To assess the short-term impact of hunting and oiling, we calculated for each realization the difference in growth rate over the second model year between populations exposed to one or more sources of mortality and ones not exposed (but with the same stochastic values of fecundity and natural mortality).

To assess the generality of our findings, we repeated the model run with a more pessimistic set of demographic parameter values, representing a population at sub-optimal conditions, which would be declining in the absence of anthropogenic mortality (values in parentheses in Table 1).

\section{Results}

\section{Age and sex distribution in the CW Greenland Shelf harvest}

The proportion of first-winter birds in the sample of shot birds from the Nuuk area was consistently much higher before 1 January (74\%) than after (24\%). There was also a considerably lower proportion of juveniles in the first part of the study period (1995-2006) than later (2007-2017; Table 3). The birds included originated from a relatively small number of samples, each of which might have a biased age distribution. We therefore pooled data from the entire study period. To estimate the overall age distribution of the harvest from the CW Greenland Shelf, we calculated a weighted mean proportion of first-winter birds based on the proportion of the total harvest reported before 1 January $(66 \%): 0.66 \times 0.74+$ $0.34 \times 0.24=57 \%$.

The sample of sexed shot birds was smaller, particularly before 1 January. The proportion of females was $39 \%$ (24/61) before 1 January, and 50\% (170/343) after 1 January. In the model, we assumed that the harvest was equally distributed between sexes.

\section{Age distribution in the Canadian harvest}

Unlike in Greenland, the annual proportion of firstwinter birds in the harvest was similar between the early season (October-December, mean 63\%) and the late season (January-March, mean 55\%) in Canada (Table 4). The proportion of first-year birds in the harvest in the late season was notably more variable, but sample sizes were also lower (Table 4). We used annual weighted means $(47 \%-77 \%$, overall mean $61 \%)$ in the model.

\section{Predicted impact of anthropogenic mortality}

The basic optimistic model scenario showed an asymptotic annual growth rate $\lambda$ of 1.053 , while $\lambda$ in the pessimistic

Table 3 The number and proportion of first-winter (FW) guillemots in the sample of shot aged birds in the Nuuk area, 1995-2017. The seasonal mean is weighted by the proportion of harvest taken before and after 1 January (66\% and 34\%, respectively).

\begin{tabular}{|c|c|c|c|c|c|c|}
\hline & \multicolumn{2}{|c|}{ Oct-Dec } & \multicolumn{2}{|c|}{ Jan-Mar } & \multicolumn{2}{|c|}{ Weighted mean } \\
\hline & $n$ & $\% \mathrm{FW}$ & $n$ & $\% \mathrm{FW}$ & $n$ & $\% \mathrm{FW}$ \\
\hline 1995-2006 & 48 & 60 & 236 & 11 & 284 & 43 \\
\hline 2007-2017 & 49 & 88 & 137 & 46 & 186 & 74 \\
\hline Total & 97 & 74 & 373 & 24 & 470 & 57 \\
\hline
\end{tabular}


Table 4 The proportion of first-winter (FW) guillemots in the sample of shot aged birds in Newfoundland and Labrador, 2010-16.

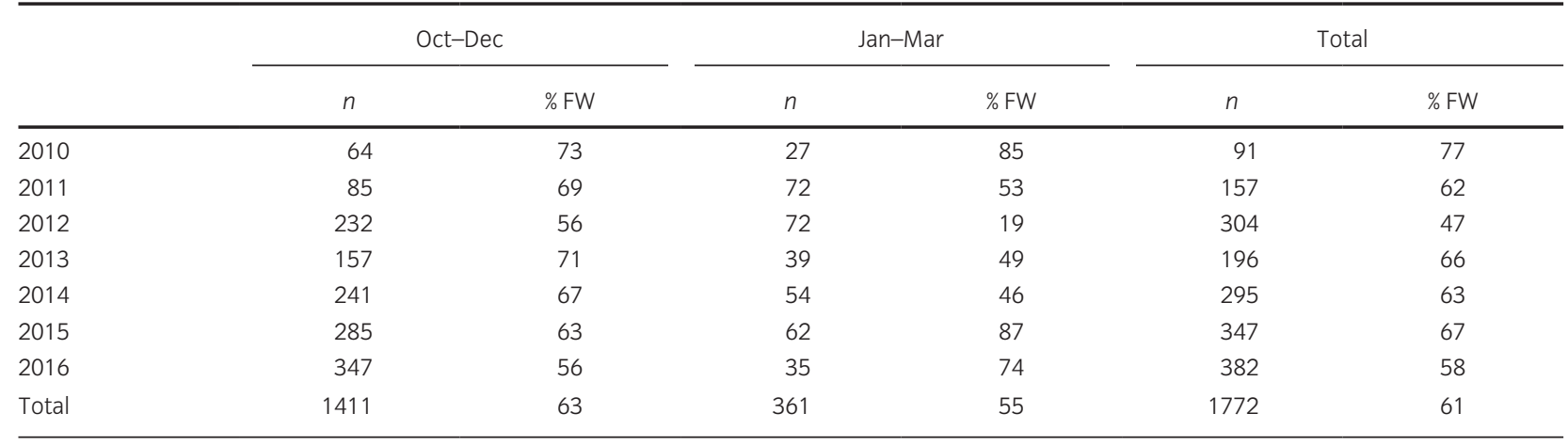


Arc_Can (Arctic Canada) Atl_Can (Atlantic Canada) Hud_Bay (Hudson Bay) NW_Gr (north-west Greenland) SW_Gr (south-west Greenland) Iceland (Iceland) Spits (Spitsbergen)

Fig. 3 The predicted impact of anthropogenic mortality on seven breeding populations of Brünnich's guillemots in the North-west Atlantic (see Fig. 1). The impact is shown as the reduction in population growth rate over the second year of the model run, based on 10000 stochastic realizations. The boxes show first and third quantiles, split by the median. The whiskers extend to either the most extreme observations or 1.5 times the length of the box, whichever is closer to the median. For clarity, outliers are not shown.

scenario was 0.976 , both in the absence of anthropogenic mortality. This corresponds to $5.3 \%$ increase and $2.4 \%$ decrease per year, respectively.

The mean predicted impact of anthropogenic mortality on growth rate of the seven breeding populations was 0.011-0.041 (Fig. 3). Hunting (all areas) caused a decline in growth rate of $0.006-0.022$, while the effect of oiling was $0-0.018$. There was considerable uncertainty around these predicted impacts, mostly caused by the high yearto-year variability in oiling mortality. The largest impact was predicted for the small breeding population in Atlantic Canada, which, to a large extent, winters on the 
Newfoundland Shelf (Fig. 2b) and is therefore exposed to mortality from both hunting and oiling. In addition, oiling and hunting in Canada had a considerable impact on the breeding population in north-west Greenland. The smallest impact was predicted for the Hudson Bay population, which largely winters further north on the Labrador Shelf. Hunting in on the CW Greenland Shelf mainly affected the Iceland breeding population, while hunting on the SW Greenland Shelf had the largest impact on the local breeding population as well as on guillemots breeding in Spitsbergen. However, the high proportion of first-year birds in the harvest on the SW Greenland Shelf led to a relatively small impact on population growth rate (Fig. 3).

The predicted impacts of anthropogenic mortality (all sources) on growth rate in the seven breeding populations were slightly $(15 \%-18 \%)$ larger under the pessimistic scenario than under the basic optimistic scenario (results not shown).

\section{Discussion}

Our estimates of the age distribution among shot guillemots on the CW Greenland Shelf, including the increase in the proportion of older birds over the season, are similar to previous studies (Falk \& Durinck 1992; Frich 1997). In Canada, the results from 2010 to 2016 are also similar to previous studies, with $53 \%$ of harvested guillemots being first-winter birds in the 1980s (Elliot et al. 1991 ) compared to $61 \%$ now. Elliot et al. (1991) noted a decline in the proportion of first-winter birds harvested in the late season in Newfoundland, but this pattern was not consistent across the province. The greater range across years in the proportion of first-winter guillemots harvested in the late season in Canada may be an indication that these later harvests are focused on different population components each year. Overall, the estimated proportion of first-winter birds on the CW Greenland Shelf and Canada was considerably higher in the harvest than in the population $(57 \%$ and $61 \%$, respectively, vs. $12.7 \%$ in the population after autumn natural mortality), indicating a higher relative hunting risk for first-winter birds.

Results from our population model show that the largest projected impact of anthropogenic mortality (0.041) was on the small breeding population in Atlantic Canada, specifically Labrador. Trend data are limited for this region, but generally this small Brünnich's guillemot breeding population appears to be variable but stable in spite of this harvest pressure, while common guillemots in Labrador are declining (Wilhelm 2017). The north-west Greenland breeding population was also affected quite strongly (projected impact on growth rate: 0.027$)$; this population is considered stable in the northern part, but strongly declining in the southern part (Merkel et al. 2014). Although the projected impact on the more easterly breeding populations in Spitsbergen, Iceland and south-west Greenland was smaller (0.011-0.018), these populations are known to be declining quite rapidly (Spitsbergen 6\%/year [Fauchald et al. 2015], Iceland 3.5\%/year [Garðarsson et al. 2019], south-west Greenland up to $4.4 \%$ /year [Merkel et al. 2014]). Projected impacts on the large Canadian Arctic breeding populations were modest (0.011-0.016), and those populations are thought to be stable (Gaston et al. 2012). Overall, harvest can thus only explain part of the observed decline of Brünnich's guillemot populations in the North Atlantic, and other factors must be involved as well (Descamps et al. 2013; Fluhr et al. 2017).

Previous assessments of the impact of harvest and oiling calculated reductions in growth rate of Canadian-breeding Brünnich's guillemots of 0.020 due to harvest and 0.025 due to oiling in the late 1990s (Wiese et al. 2004). Our results showed reduced effects, likely due to a number of factors. Firstly, the population size of Canadian breeders is now larger than the estimates used in Wiese et al. (2004). In addition, harvest levels and especially oiling mortality have declined considerably since the late 1990s (Robertson et al. 2014; Frederiksen et al. 2016).

\section{Model limitations}

Not all sources of uncertainty were included in our stochastic model. In particular, we treated the composition of wintering populations as known without error. This is obviously not the case; positions derived through geolocation are quite imprecise (Phillips et al. 2004), the samples of tracked birds were relatively small for some populations and some very large colonies were not represented (Frederiksen et al. 2016). In addition, we had no data on winter distribution of pre-breeding guillemots and therefore assumed that they behave like adult breeders. Nevertheless, the overall patterns accord well with all other information on guillemot winter distribution (e.g., ring recoveries; Bakken et al. 2003; Lyngs 2003; Gaston \& Robertson 2014), and we are confident that our main conclusions regarding impacts on specific breeding populations are robust. New tracking data not included here indicate that guillemots from Jan Mayen winter off south-west Greenland and north of Iceland (SEAPOP 2018), and that a few Icelandic birds winter on the Newfoundland Shelf (Linnebjerg et al. 2018); including this information in the model would slightly change the predicted impacts of anthropogenic mortality. Further work using biological markers and next-generation DNA sequencing is underway to directly assign harvested birds 
to source colonies and corroborate harvest derivations based on the tracking data.

Although the overall conclusions and relative magnitude of the impacts of harvest were consistent across different demographic conditions (growing vs. declining populations), the input vital rates were collated from limited sources, and for post-fledging rates, parameter values from common guillemots were used. Without robust site-specific monitoring and demographic data, our models cannot effectively predict whether any particular colony or region is growing or declining, nor assess accurately the potential effect of a mortality source at any one site. However, for understanding the potential overall relative effect of mortality sources, we believe that our approach is robust and sufficient.

Furthermore, the predicted impacts of mortality sources are only as good as the estimates used. Estimates for harvest in Greenland and Canada are likely to be reasonable, as both are based on large-scale harvest surveys. However, these surveys are not perfect and are known to have certain biases. The extent of crippling loss, that is, birds dying as a result of shooting, but not retrieved by hunters (Byers $\&$ Dickson 2001), is unknown, and the impact of harvest is therefore likely underestimated. Guillemot hunting is carried out from small open boats in the ocean, under a range of winter weather and sea states, and guillemots often dive when shot at; these factors make retrieval of all targeted birds unlikely, and estimates of crippling loss would be a useful addition. A major issue for Canada remains illegal harvest, often followed by the illegal sale of guillemots to the public. Wildlife enforcement officers in Canada suggest that the illegal harvest may be as high as the estimated legal and reported harvest. Addressing this illegal harvest is a priority for Canadian guillemot conservation efforts. In Greenland, underreporting of harvest may be an issue, but this has not been quantified. Illegal spring harvest is known to occur, but is probably quite limited. Sex ratios of guillemots taken in the harvest are also not well estimated, and limited evidence from Canada suggested a male bias among juveniles (McFarlane Tranquilla et al. 2010). More work on assessing the overall sex ratio of harvested guillemots is needed to ensure assumptions of equal sex ratio are empirically based. Guillemots show obligate bi-parental care, and any sexual imbalance in hunting or oiling mortality would lead to an inflated impact on population size and annual growth rate.

Oiling mortality from chronic sources in Canada, on the contrary, appears to be continuing to decline, to the point where so few oiled carcasses are now found in beached bird surveys that estimating mortality from oiling is challenging (Robertson et al. 2014). Changes to Canadian and international maritime law, coupled with improved environmental practices in the maritime shipping industry, appear to have had the desired effects of reducing seabird mortality from ship-source oil pollution in eastern Canadian waters. Given the continued decline in numbers of oiled birds detected in Newfoundland, our assessment of the impact of oiling is likely an overestimate.

\section{Implications for management}

This study clearly demonstrates that anthropogenic mortality (hunting and oiling) of guillemots in the wintering areas affects breeding populations in most of the Atlantic range. In most cases, the breeding populations concerned are affected by mortality in a different country. A large proportion of the harvest in Greenland is directed at declining populations in south-west Greenland, Spitsbergen and Iceland. A total hunting ban on guillemots in Greenland, which would benefit both local breeding populations and those in Iceland and Spitsbergen, was recommended by Merkel et al. (2014). This recommendation has not been implemented, but from 2017 the winter hunting season was shortened from 4.5 to 1.5 months (1 November-15 December). In Canada, efforts should be concentrated on determining more precisely which breeding populations are impacted, and if there are particular times or locations at which the harvest targets these declining populations. The legal harvest in Canada does affect populations breeding in north-west Greenland, where several colonies in the southern part are declining strongly. Furthermore, efforts to reduce illegal harvests of guillemots for the purposes of commercial selling in Canada must be a priority. Brünnich's guillemots are also harvested in Iceland, albeit in considerably smaller numbers than in Greenland and Canada (Frederiksen et al. 2016). Available information on the seasonal and age distribution of this harvest is limited.

International coordination is a prerequisite for successful harvest management of Atlantic guillemots. Specific attention should be directed at the declining and Red-listed breeding populations in Spitsbergen, Iceland and south-west Greenland. Although anthropogenic mortality in the wintering areas can explain only a part of the observed decline in these populations, principles of sustainable harvesting would suggest that hunting should be suspended until populations have stabilized and started to recover.

\section{Acknowledgements}

The authors thank Sigga Joensen, Annika Strömberg, Maia Olsen and Else Ostermann for help with dissections, and also thank all Canadian hunters who participate in 
the harvest and species composition surveys as well as Michel Gendron, Scott Gilliland, Pierre Ryan and Bruce Pollard for their contribution in implementing and managing the murre species composition survey, and Sébastien Descamps for useful comments on an earlier version.

\section{Disclosure statement}

No potential conflict of interest was reported by the authors.

\section{Funding}

This study was supported by a grant from the Aage V. Jensen Charity Foundation to MF. Harvest surveys in Canada are conducted by the Canadian Wildlife Service of Environment and Climate Change Canada.

\section{References}

Bakken V., Runde O. \& Tjørve E. 2003. Norsk ringmerkingsatlas. (Norwegian bird ringing atlas.) Vol. 1. Stavanger, Norway: Stavanger Museum.

Byers T. \& Dickson D.L. 2001. Spring migration and subsistence hunting of king and common eiders at Holman, Northwest Territories, 1996-98. Arctic 54, 122-134, http:// dx.doi.org/10.14430/arctic771.

Cadiou B., Riffaut L., McCoy K.D., Cabelguen J., Fortin M., Gélinaud G., Le Roch A., Tirard C. \& Boulinier T. 2004. Ecological impact of the "Erika" oil spill: determination of the geographic origin of the affected common guillemots. Aquatic Living Resources 17, 369-377, http://dx.doi. org/10.1051/alr:2004036.

Caswell H. 2001. Matrix population models. Construction, analysis, and interpretation. Sunderland, MA: Sinauer.

Descamps S., Strøm H. \& Steen H. 2013. Decline of an Arctic top predator: synchrony in colony size fluctuations, risk of extinction and the subpolar gyre. Oecologia 173, 1271-1282, http://dx.doi.org/10.1007/s00442-013-2701-0.

Donaldson G.M., Gaston A.J., Chardine J.W., Kampp K., Nettleship D.N. \& Elliot R.D. 1997. Winter distributions of thick-billed murres from the eastern Canadian Arctic and western Greenland in relation to age and time of year. Canadian Wildlife Service Occasional Papers 96. Ottawa: Environment Canada.

Elliot R.D., Collins B.T., Hayakawa E.G. \& Metras L. 1991. The harvest of murres in Newfoundland from 1977-78 to 1987-88. In A.J. Gaston \& R.D. Elliot (eds.): Studies of high-latitude seabirds. 2. Conservation biology of thickbilled murres in the Northwest Atlantic. Pp. 36-44. Ottawa: Canadian Wildlife Service.

Esler D. 2000. Applying metapopulation theory to conservation of migratory birds. Conservation Biology 14, 366-372, http://dx.doi.org/10.1046/j.1523-1739.2000.98147.x.

Falk K. \& Durinck J. 1992. Thick-billed murre hunting in west Greenland. Arctic 45, 167-178, http://dx.doi. org/10.14430/arcticl390.
Fauchald P., Anker-Nilssen T., Barrett R.T., Bustnes J.O., Bårdsen B.-J., Christensen-Dalsgaard S., Descamps S., Engen S., Erikstad K.E., Hanssen S.A., Lorentsen S.-H., Moe B., Reiertsen T.K., Strøm H. \& Systad G.H. 2015. The status and trends of seabirds breeding in Norway and Svalbard. NINA Report 1151. Tromsø: Norwegian Institute for Nature Research.

Fluhr J., Strøm H., Pradel R., Duriez O., Beaugrand G. \& Descamps S. 2017. Weakening of the subpolar gyre as a key driver of North Atlantic seabird demography: a case study with Brünnich's guillemots in Svalbard. Marine Ecology Progress Series 563, 1-11, http://dx.doi.org/10.3354/ meps11982.

Frederiksen M., Descamps S., Erikstad K.E., Gaston A.J., Gilchrist H.G., Grémillet D., Johansen K.L., Kolbeinsson Y., Linnebjerg J.F., Mallory M.L., McFarlane Tranquilla L.A., Merkel F.R., Montevecchi W.A., Mosbech A., Reiertsen T.K., Robertson G.J., Steen H., Strøm H. \& Thórarinsson T.L. 2016. Migration and wintering of a declining seabird, the thick-billed murre Uria lomvia, on an ocean basin scale: conservation implications. Biological Conservation 200, 26-35, http://dx.doi. org/10.1016/j.biocon.2016.05.011.

Frederiksen M., Moe B., Daunt F., Phillips R.A., Barrett R.T., Bogdanova M.I., Boulinier T., Chardine J.W., Chastel O., Chivers L.S., Christensen-Dalsgaard S., Clément-Chastel C., Colhoun K., Freeman R., Gaston A.J., González-Solís J., Goutte A., Grémillet D., Guilford T., Jensen G.H., Krasnov Y., Lorentsen S.-H., Mallory M.L., Newell M., Olsen B., Shaw D., Steen H., Strøm H., Systad G.H., Thórarinsson T.L. \& Anker-Nilssen T. 2012. Multi-colony tracking reveals the winter distribution of a pelagic seabird on an ocean basin scale. Diversity and Distributions 18, 530-542, http://dx.doi.org/10.1111/j.1472-4642.2011.00864.x.

Frich A.S. 1997. Lomviefangst i Nuuk vinteren 1995/96. (Murre harvest in Nuuk, winter 1995/96.) Teknisk Rapport 4. Nuuk: Greenland Institute of Natural Resources.

Garðarsson A., Guðmundsson G.A. \& Lilliendahl K. 2019. Svartfugl í íslenskum fuglabjörgum 2006-2008. (The numbers of large auks on the cliffs of Iceland in 2006-2008.) Bliki 33, 35-46.

Gaston A.J. \& Hipfner J.M. 2000. Thick-billed murre (Uria lomvia). In A. Poole (ed.): The birds of North America online. Pp. 1-32. Ithaca: Cornell Lab of Ornithology, http:// dx.doi.org/10.2173/bna.497.

Gaston A.J., Mallory M. \& Gilchrist H.G. 2012. Populations and trends of Canadian Arctic seabirds. Polar Biology 35, 1221-1232, http://dx.doi.org/10.1007/s00300-012-1168-5.

Gaston A.J. \& Robertson G.J. 2010. Trends in the harvest of Brünnich's guillemots Uria lomvia in Newfoundland: effects of regulatory changes and winter sea ice conditions. Wildlife Biology 16, 47-55, http://dx.doi.org/ 10.2981/09-020.

Gaston A.J. \& Robertson G.J. 2014. A review of thick-billed murre banding in the Canadian Arctic, 1950-2010. Arctic 67, 441-448, http://dx.doi.org/10.14430/arctic4419.

Gendron M.H. \& Smith A.C. 2017. National Harvest Survey. Bird populations monitoring. Ottawa, Ontario: National Wildlife Research Centre, Canadian Wildlife Service. 
Accessed on the internet at http://ec.gc.ca/reom-mbs/enpnhs/index.cfm?do=defflang=e on 5 March 2018.

Gilliland S.G., Gilchrist H.G., Rockwell R.F., Robertson G.J., Savard J.P.L., Merkel F. \& Mosbech A. 2009. Evaluating the sustainability of harvest among northern common eiders Somateria mollissima borealis in Greenland and Canada. Wildlife Biology 15, 24-36, http://dx.doi. org/10.2981/07-005.

Government of Canada 2017. Establishing national regulations for migratory game bird hunting: objectives and guidelines. Ottawa, Ontario: Canadian Wildlife Service. Accessed on the internet at https://www.canada.ca/en/environment-climate-change/ services/migratory-game-bird-hunting/consultationprocess-regulations/establishing-national-objectivesguidelines.html on 16 January 2019.

Harris M.P., Frederiksen M. \& Wanless S. 2007. Within- and between-year variation in the juvenile survival of common guillemots Uria aalge. Ibis 149, 472-481, http://dx. doi.org/10.1111/j.1474-919X.2007.00667.x.

Linnebjerg J.F., Frederiksen M., Kolbeinsson Y., Snaethórsson A.Ö., Thórisson B. \& Thórarinsson T.L. 2018. Non-breeding areas of three sympatric auk species breeding in three Icelandic colonies. Polar Biology 41, 1951-1961, http://dx. doi.org/10.1007/s00300-018-2334-1.

Lyngs P. 2003. Migration and winter ranges of birds in Greenland. An analysis of ringing recoveries. Dansk Ornitologisk Forenings Tidsskrift 97(1). Copenhagen: Danish Ornithological Society.

McFarlane Tranquilla L., Hedd A., Burke C., Montevecchi W.A., Regular P.M., Robertson G.J., Stapleton L.A., Wilhelm S.I., Fifield D.A. \& Buren A.D. 2010. High Arctic sea ice conditions influence marine birds wintering in Low Arctic regions. Estuarine, Coastal and Shelf Science 89, 97-106, http://dx.doi.org/10.1016/j.ecss.2010.06.003.

Merkel F., Labansen A.L., Boertmann D., Mosbech A., Egevang C., Falk K., Linnebjerg J.F., Frederiksen M. \& Kampp K. 2014. Declining trends in the majority of Greenland's thick-billed murre (Uria lomvia) colonies 1981-2011. Polar Biology 37, 1061-1071, http://dx.doi. org/10.1007/s00300-014-1500-3.

Nevins H.M. \& Carter H.R. 2003. Age and sex of common murres Uria aalge recovered during the 1997-98 Point Reyes tarball incidents in central California. Marine Ornithology 31, 51-58.

Péron G. 2013. Compensation and additivity of anthropogenic mortality: life-history effects and review of methods. Journal of Animal Ecology 82, 408-417, http://dx.doi. org/10.1111/1365-2656.12014.

Phillips R.A., Silk J.R.D., Croxall J.P., Afanasyev V. \& Briggs D.R. 2004. Accuracy of geolocation estimates for flying seabirds. Marine Ecology Progress Series 266, 265-272, http:// dx.doi.org/10.3354/meps266265.

Priest H. \& Usher P.J. 2004. The Nunavut wildlife harvest study. Iqaluit, Nunavut: Nunavut Wildlife Management Board.

Robertson G.J., Ryan P.C., Dussureault J., Turner B.C., Wilhelm S.I. \& Power K. 2006. Composition of beached marine birds from an oiling event in southeastern Newfoundland, November 2004. Marine Ornithology 34, 141-146.

Robertson G.J., Wiese F.K., Ryan P.C. \& Wilhelm S.I. 2014. Updated numbers of murres and dovekies oiled in Newfoundland waters by chronic ship-source oil pollution. Proceedings of the 37th AMOP Technical Seminar on Environmental Contamination and Response. Pp. 265-275. Ottawa: Environment Canada.

SEAPOP 2018. Brünnich's guillemots (Uria lomvia). Accessed on the internet at http://www.seapop.no/en/ seatrack/\#brunnichs-guillemot on 6 June 2019.

Smith P.A. \& Gaston A.J. 2012. Environmental variation and the demography and diet of thick-billed murres. Marine Ecology Progress Series 454, 237-249, http://dx.doi. org/10.3354/meps09589.

Stubben C.J. \& Milligan B.G. 2007. Estimating and analyzing demographic models using the popbio package in R. Journal of Statistical Software 22, 1-23, http://dx.doi.org/10.18637/ jss.v022.i1 1 .

Wiese F.K. 2002. Estimation and impacts of seabird mortality from chronic marine oil pollution off the coast of Newfoundland. PhD thesis, Dept. of Biology, Memorial University of Newfoundland, St. John's, Newfoundland, Canada

Wiese F.K. 2003. Sinking rates of dead birds: improving estimates of seabird mortality due to oiling. Marine Ornithology $31,65-70$.

Wiese F.K. \& Jones, I.L. 2001. Experimental support for a new drift block design to assess seabird mortality from oil pollution. Auk 118, 1062-1068, http://dx.doi. org/10.2307/4089860.

Wiese F.K. \& Robertson G.J. 2004. Assessing seabird mortality from chronic oil discharges at sea. Journal of Wildlife Management 68, 627-638, http://dx.doi.org/10.2193/0022541X(2004)068[0627:ASMFCO]2.0.CO;2.

Wiese F.K., Robertson G.J. \& Gaston A.J. 2004. Impacts of chronic marine oil pollution and the murre hunt in Newfoundland on thick-billed murre Uria lomvia populations in the eastern Canadian Arctic. Biological Conservation 116, 205-216, http://dx.doi.org/10.1016/ S0006-3207(03)00191-5.

Wiese F.K. \& Ryan P.C. 2003. The extent of chronic marine oil pollution in southeastern Newfoundland waters assessed through beached bird surveys 1984-1999. Marine Pollution Bulletin 46, 1090-1101, http://dx.doi.org/10.1016/ s0025-326x(03)00250-9.

Wilhelm S. 2017. CWS: Waterbird colony database (Atlantic region). Version 1. OBIS Canada Digital Collections. Dartmouth, NS, Canada: Bedford Institute of Oceanography. Accessed on the internet on http:/ipt.iobis.org/ obiscanada/resource?r=cws_atlantic_colonydbase on 18 April 2018.

Wilhelm S.I., Gilliland S.G., Robertson G.J., Ryan P.C. \& Elliot R.D. 2008. Development and validation of a wing key to improve harvest management of alcids in the Northwest Atlantic. Journal of Wildlife Management 72, 1026-1034, http://dx.doi.org/10.2193/2007-232. 